\title{
A study on Tea Dyeing Materials Technical Innovation and the Trend of Its Application
}

\author{
Qin-ru Huang ${ }^{1}$, and Chun-hua $\mathrm{Gu}^{2}$ \\ ${ }^{1}$ College of Textile and Garment, Anhui Polytechnic University \\ ${ }^{2}$ College of Textile and Garment, Anhui Polytechnic University
}

Keywords: Tea Dyeing Technology, Tea Dyeing Culture, Gatherings of Literati.

\begin{abstract}
In hope that the ancient traditional tea dyeing which borders on dyeing away could thrive again with the revival of traditional Chinese culture and handicraft, the writer has done a lot of researches into and experiments on tea dyeing and the application of the theories concerned. A rational exploitation and utilization of natural resources, and a combination of our ancestors' wisdoms with new materials and technology can bring green and healthy colors of nature back to modern life, so as to invest Chinese fashion design with concerns about ecology and humanity.
\end{abstract}

\section{Introduction}

Tea dyeing makes use of the dyeing property of tea to change the color array of the textiles. An analysis of the available records shows that tea dyeing is a development and derivation of plant dyeing, with a variation in dyeing materials.

Against a background of the development of modern environmental-friendly fashion design and cultural ecology, and the revival of traditional Chinese costume, the paper aims to provide a new way to protect and improve our living environment in a sustainable way, by integrating the artistry and practicality of tea dyeing with fashion design for literati, to replace the modern high pollution industrial civilization with a new low-carbon ecologicalcivilization.

\section{The Heritage of Tea Dyeing}

\section{The Traditional Tea Dyeing Technology}

Tea dyeing technology can be divided into three types, according to the writer's researches.

\section{Dyeing with Dye Liquor Extracted from Tea}

Put dry tea leaves into distilled water, boil them, and filter them to get the dye liquor, and submerge the textiles into the liquor. This way can help control and improve the quality and effect of the dyeing, with the preliminary process of the liquor.

\section{Dyeing with Tea Without Filtering}

In Yi Yuji, an ancient book about forensic practices, written by HeNing in 951, it mentions the effect of tea dyeing on paper, which is the origin of the technology.[1]Boil some tea with water, submerge the textiles into the water, adjust the temperature and moisture to provide different conditions to achieve different effect of dyeing.

\section{Dyeing with Mordant}

Add mordant into dyeing liquor which has been processed preliminarily to produce chemical reaction. Among mordants, $\mathrm{Cu}(\mathrm{so} 4) \cdot 5 \mathrm{H} 2 \mathrm{O}, \mathrm{Fe}$ ( so ) $4 \cdot 7 \mathrm{H} 2 \mathrm{O}, \mathrm{Al}(\mathrm{CH} 3 \mathrm{COO}$ ) 3 are most frequently used and they can promote the effect of dyeing especially on tussah and polyamide fiber. Among the dyeing technology, mordant dyeing is the one that enhances the quality and efficiency of dyeing to the highest point, in achieving different color arrays of high quality and enriching the ways of expression of fashion design. 


\section{Innovation of Tea Dyeing Material and Technology}

\section{Innovation of Tea Dyeing Material}

Tea culture has a deep and far-reaching influence over China and the world. The color of tea is natural, quaint, delicate, and quiet. Textiles dyed with tea present a different esthetic style in color, pattern, and smell. The choice of dyeing material being unlimited, it could be the remains of used tea leaves, broken tea leaves, tea leaves preserved for long time and overgrown tea leaves, all of which could make good materials. In the experiment, the writer chooses green tea for its low Theophylline, which is suitable to be a background color.[2] Tomato, grape, onion and other fresh fruits and plants of easy access in daily life could be added infor a wider range of colors and modern esthetic appeal. Boiling the materials together, put the textiles in the filtered dyeing liquor, processing with cold dyeing and hot dyeingand tie wash for different effects of coloration (as illustrated in Figure 1).

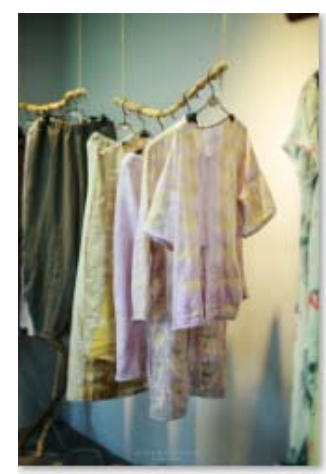

(a)

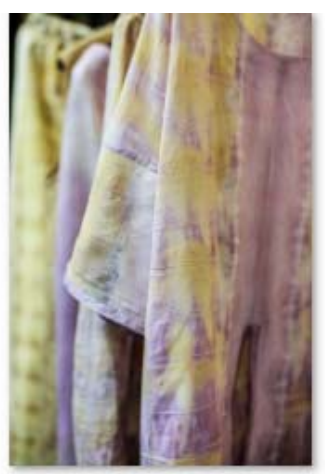

(b)

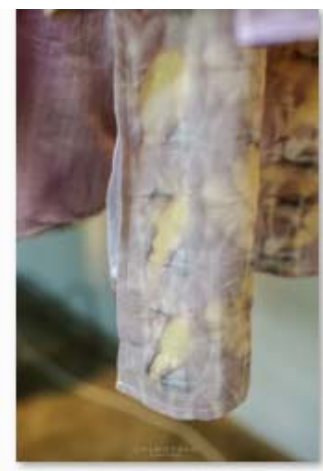

(c)

Figure1 The effect of coloration of tea dyeing combined with plant dye

The quiet and quaint colors of tea combined with bright and brilliant colors of plants render the textiles a unique style, a mixture of ancientsimplicity and delicacy of tea, and modernity and fashion of rich bright colors.

\section{Innovation of Tea Dyeing Technology_Plant Transfer Printing and Dyeing}

Records show that plant dye has a long history in China, and now it can satisfy the high demand of people for a healthy quality life in modern society. In the experiment, the writer uses plant transfer printing and dyeing by adoptingthe process of cold dyeing and hot dyeing, witheucalyptus leaves. Dye silk fabric with tea liquor that has been boiled and filtered, put eucalyptus leaves one by one on the fabric in the designed pattern, roll it up, submerge it into cold tea liquor for 24 hours (as illustrated in picture 2). Patterns of leaves will be on the fabric clean and clear, to lend a natural aura to the clothes made of it, especially Zen tea clothing.

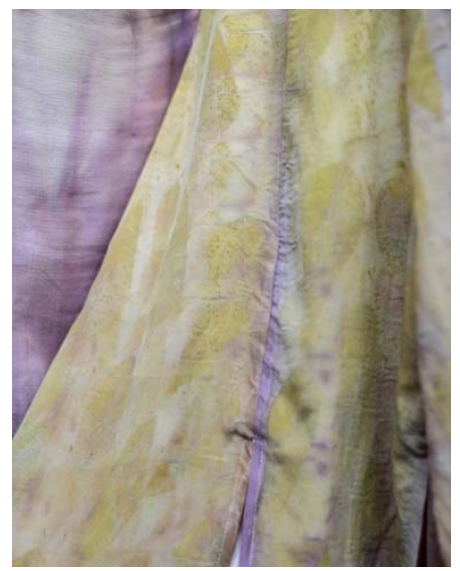

Figure2Plant transfer printing and dyeing 


\section{Chinese Culture of Tea and Tea Dyeing}

In the thousands of years of historical development of China, there are diverse refined arts and culture of spiritual significance, tea culture standing out among them. China's tea culture involves not only culture, but also aesthetic; it's not only a form of material culture, but also a form of non-material culture.[3]

With the development of tea culture and the design of Zen tea clothing, the inherent aesthetic characteristics of tea dyeing have been continuously enriched and extended. Being natural, simple, delicate, quaint, quiet, meditative, and tinted with a restrained modesty and rich variation,tea dyeing goes in line with the Chinese nation's cultural spirit, which serves as a psychological basis for the development of tea dyeing.[4]Since the beginning of the new century, tea dyeing has underwent a new development in color, texture, material, patterns and aesthetic appeal,and has begun to penetrate into the modern fashion design, to produce a new pattern of diverse development. It is particularly important that the modern concept of living a green and healthy life, and a pursuit of peace of mind instead of psychological restlessness, provide a broad prospect for the development of tea dyeing.

\section{Application Trends of Innovative Techniques of Tea Dyeing in Gatherings of Literati}

\section{Gatherings of Literati}

In the traditional Chinese cultural life, the literati have diverse cultural and social activities, among whichgatherings of literati, where the literati share their literary works and arts with friends of the same interest and taste. Itis a vivid portrayal and cultural landscape of China. Growing and developing as a legendary tradition in Chinese literature and arts, Gatherings of literati, especially held in Lanting, Yushan and Xiyuan, the most influential ones, have produced a large number of excellent literary worksand arts.

The traditional gatherings of literati are generally held and participated exclusively by the literati, featuring activities of recitation of poems, academic discussions, and other literary and artistic activities like playing Guqin (a traditional Chinese instrument with seven strings), tasting tea, smelling incense, and appreciating painting and calligraphy. Tea ceremony has become an important part of moderngatherings of literati.

\section{The Essential Features of the Clothing of Gatherings of Literati}

\section{Color Rendering Designed to Display the Connotation and Temperament of the Literati}

In Chinese traditional culture and social system, the literati are often people with elegant temperament, of high status, great knowledge, and cultivation. In the gatherings, clothing is not only a decoration of one's physical appearance but a reflection of one's spiritual connotation. With the development of the social environment and the revival of the traditional Chinese culture, the modern literati begin to get out of the unworldlyivory tower of scholars to be open to nature with awe, which calls for a natural and simple style for their clothing.

To present clothing of gatherings of literati as being clean, elegant and quiet, selection of colorsshould highlight its natural style, which is in line with the clean, simple and delicate colors of tea dyeing. The colors of tea dyeing are more like a symbol of culture, and a media of cultural communication by way of fashion design.

\section{Patterns Designed to Display Spiritual Connotation and Aesthetic Appeal}

The activities of the gatherings of literati feature appreciation of literary and artistic works, which involve poetry, books, prose, tea, and other artistic performance. Tea ceremony and its clothing are a very important part. Tea culture thrived in Tang Dynasty, which saw a further development of the clothing of the gatherings of literati in texture, material, and color. Influenced later by the aesthetics of Song Dynasty and Yuan Dynasty,patterns of the clothing tended to display both the spiritual connotation of the literati and aesthetic appeal in the details and the overall pattern of the clothing. 


\section{Application Trends of Innovative Techniques of Tea Dyeing in Gatherings of Literati}

Gatherings of literati are an important part of the continuation and development of Chinese culture, and the natural colors of tea dyeing lend a traditional elegance to the clothing. The colors and patterns of the tea dyed clothing are a physical expression of tea culture and its further development.[5]

Tea dyeing could be a reflection of the cultivation of the literati, and the culture and psychology of colors. It should put more focus on expression of the connotation and temperament of literati, besides its aesthetic values. [6] When tea dyeing goes together with gatherings of literati, it shows the world the beauty of natural colors, giving visual pleasure, and it also provides an interpretation of tea culture, gatherings of literati and Chinese tradition, giving spiritual enlightenment.

In the development of the Chinese traditional culture, gatherings of literati play a very important role. Being an important and indispensible part of the gathering, clothing adds more appeal and thoughts to the gatherings. It is important for the fashion designers to choose the proper way to express the connotation and temperament of the literati and help them to build a world of literature and arts, in which tea dyeing has many advantages as being natural and simple.

\section{Acknowledgement}

This research was financially supported by the AnhuiPolytechnic University Youth Fund project (KZ00316043). This research was financially supported by the Anhui university social and $\mathrm{h}$ umanity science project (SK2015A274).

\section{References}

[1]Guan Jianping, Tea and Chinese culture, Beijing, People’s Publishing House, 2001.

[2] Information on http://www.indiaflint.com

[3] KeGuizhen, Yu Weidong, XuWeilin, Characteristics and function realization of medical plant dyes Part (I): Pharmacology, Chromaticity and Dyeing, Journal of Wuhan University of Science and Engineering, 2006(01).

[4] Nannette Holmberg, Re-inventing chenille, fresh sewing techniques and project, 2009.

[5]Yao Dandan, Wang Chunxia, Chu Liqun, Fu Shaohai, Dyeing of silk fabric with natural dyes from Yunnan grass plant, Dyeingand Finishing. 2009(22).

[6]Zhu Haiyan, Study on Chinese tea aesthetics__ tea aesthetics in the Tang and Song Dynasties and the construction of contemporary tea aesthetics, Doctoral dissertation of Hunan Agricultural University,2008. 